\title{
BONE LOSS AROUND MANDIBULAR IMPLANT SUPPORTED OVERDENTURES. A SEVEN YEAR FOLLOW UP
}

\author{
Mohamed Farouk Abdalla* and Nagla Nassouhy ${ }^{* *}$
}

\begin{abstract}
Introduction: The number of implants required to stabilize an overdenture has always been a question worth addressing, particularly when economic issues are of concern. Four implants have been used successfully to support a mandibular overdenture, however the type of attachment used may affect the outcome of implant survival and bone anatomy around the implants.
\end{abstract}

Materials and methods: Eight patients were chosen. All patients were completely edentulous, with their maxillary arches restored with conventional dentures. The mandibular arch was restored with a metal reinforced acrylic resin overdenture supported by four implants.

The implants were placed at the lateral and first premolar areas (Implant direct, Legacy II). Four patients received low profile attachments (Locator Abutment, Implant Direct, Legacy II) (fig 1) and four patients received ball attachments (Ball Abutment, Implant Direct, Legacy II). Over the next 7 years annual bone measurements were taken by measuring from the implants apex to the level of the bone. implant stability was also checked and recorded by placing the smart peg and using ISQ measurements (Ostell).

Results: using independent $\mathrm{t}$ test, bone loss around distal implants in both groups were significant especially in the locator group. The stability measurements showed no statistical significance over the course of 7 years.

Conclusion: Long term follow up on mandibular overdentures supported by four solitary implants, regardless of the attachment, have shown good implant stability, however, significant bone loss around the most distal implants is to be expected.

KEYWORDS: over denture, 4 implants, locator, ball abutment

* Ass. Prof Prosthodontic Department Cairo University.

** Ass. Prof Prosthodontic Department New Giza University. 


\section{INTRODUCTION}

Complete edentulism remains to be a commonly occurring health issue. The conventional treatment with complete dentures has always been associated with a number of functional, esthetic and psychological problems. A common complaint of complete denture wearers, especially with the mandibular denture, is denture movement, probably due to low stability and retention ${ }^{1}$. The stabilization of mandibular dentures with dental implants has been a common practice for the past 20 years ${ }^{2}$. Two implant overdentures have now been recommended as the minimum standard of care for prosthetic rehabilitation of completely edentulous mandibular arches as per the McGill consensus statement ${ }^{3}$.

The number of implants required to stabilize an overdenture has always been a question worth addressing, particularly when economic issues are of concern.

The number of implants supporting a mandibular overdenture have ranged from one to four implants. Several authors have argued that two implants with solitary ball abutments are enough to retain and stabilize an overdenture. They are also less technique sensitive and more economical ${ }^{4-7}$.

However, it should be noted that when only two implants are used, the degree of overdenture movement can be greater, resulting in higher need for maintenance, such as relining and cap renewal, than that needed when a greater number of implants are used ${ }^{8}$. Therefore, increasing the number of supporting implants was recommended by some authors, especially in cases with increased occlusal loads, the need for higher retention and when the implant lengths are less than $8 \mathrm{~mm}$ or with a width less than $3.5 \mathrm{~mm}^{9}$.

Four implants have been used successfully to support a mandibular overdenture, however the type of attachment used may affect the outcome of implant survival and bone anatomy around the implants. Ball and Locator attachments have always been the first attachments of choice in implant overdentures due to their simplicity, and cost effectiveness ${ }^{10-12}$.

In another context, implant success depends greatly on implant stability, which can be measured by several tools and techniques ${ }^{13}$. One of these techniques is the resonance frequency analysis (RFA). RFA is a simple, non-invasive procedure consisting of a transducer that emits a certain signal that causes the implant to vibrate. The resistance of the implant to this vibration is recorded by the intended device and configured into implant stability quotient (ISQ) values. ISQ is then measured on a scale within $0-100,100$ being the highest, and 0 being the lowest stability values ${ }^{14}$. The OSSTELL ISQ, produced in 2009, is one of the most commonly used RFA devices. Osstell findings are considered reliable and sufficient to assess the status of implant success and survival ${ }^{15-17}$.

The null hypothesis to be challenged in this study is that there is no difference between locator and ball attachments, regarding bone loss, and implant stability, when used in mandibular overdentures supported by 4 implants, over the course of seven years.

\section{MATERIALS AND METHODS}

Eight patients were chosen, male, with an age range of 45-50 years. All patients had no systemic disease or bony malformations that could affect implant placement. All patients were completely edentulous, with their maxillary arches restored with conventional dentures. The mandibular arch was restored with a metal reinforced acrylic resin overdenture supported by four implants.

The implants were placed at the lateral and first premolar areas (Implant direct, Legacy II). Four patients received low profile attachments (Locator Abutment, Implant Direct, Legacy II) (fig. 1) and four patients received ball attachments (Ball 
Abutment, Implant Direct, Legacy II) (fig 2). After second stage surgery and healing abutment insertion, steps of overdenture construction were commenced including primary alginate impressions, secondary rubber base addition silicone impressions, metal try-in of overdenture framework, face bow records and jaw relation records and finally artificial teeth try-in.

Then, overdenture pickup and delivery was performed in the following manner: relieving the areas opposite the attachments was done and rubber dam pieces and pickup spacers were placed around the attachments, followed by filling the relieved areas with cold cure acrylic and picking up the housings while the patient is biting softly in centric

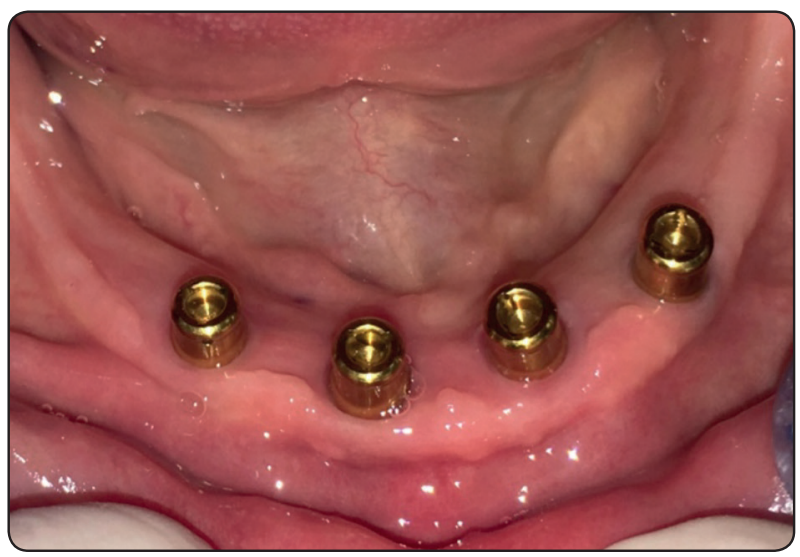

Fig. (1) Intraoral picture of four mandibular implants with locator attachments.

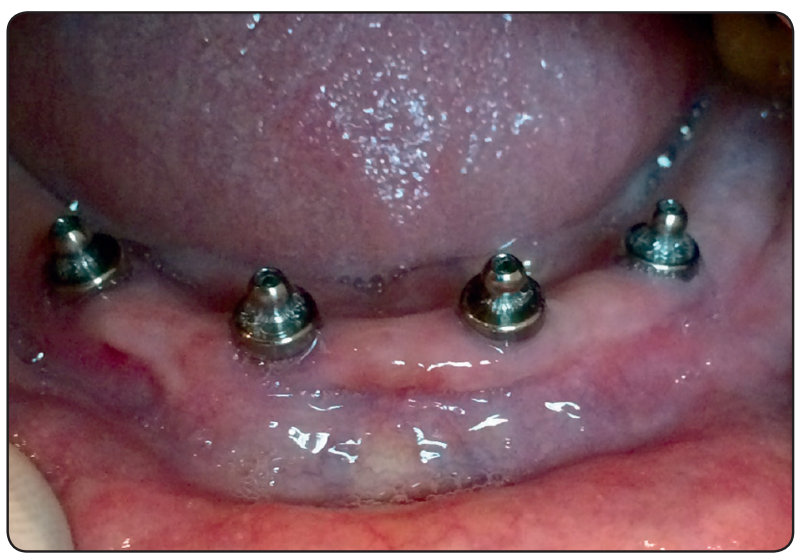

Fig. (2) Intraoral picture of four mandibular implants with ball attachments. relation position. In the locator group, the black processing caps used in the pickup procedure were replaced with orange medium retention caps. (fig 3 and 4)

Digital periapical $\mathrm{x}$-rays were taken of each implant using an acrylic film holder for standardization. Bone measurements were taken by measuring from the implants apex to the level of the bone both mesial and distal to the implant and calculating the average. X-rays were repeated on annual basis for a period of seven years. (fig 5 and 6) Bone loss was later calculated by subtracting the annual measurements from the first base line measurement taken when loading the overdenture was done. In addition, during the same period,

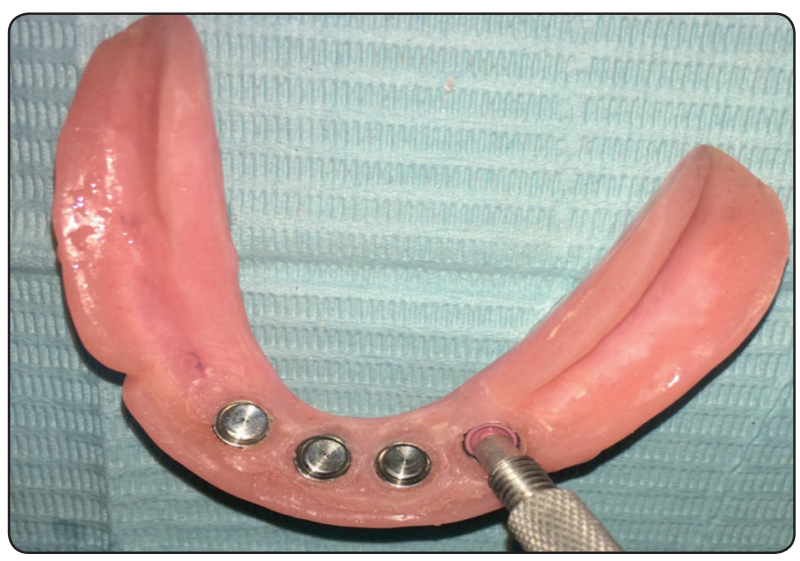

Fig. (3) Extraoral picture of retentive cap insertion in the locator housing.

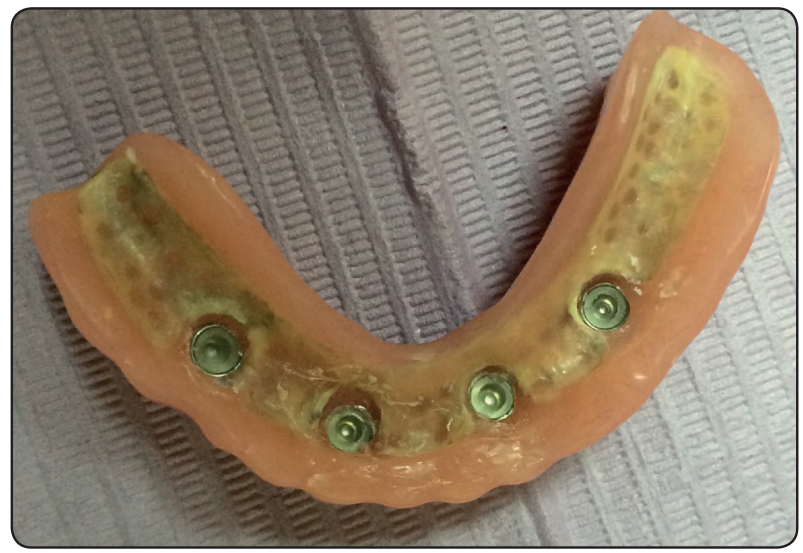

Fig. (4) Extraoral picture of retentive cap in the ball housing. 


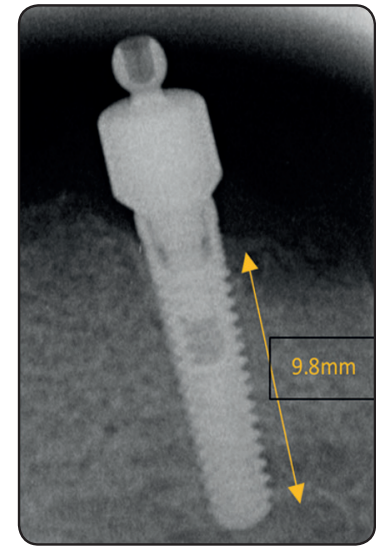

Fig. (5) : Bone height measurement for implant with ball attachment.

implant stability was also checked and recorded by placing the smart peg and using ISQ measurements (Ostell), the average of the buccal, lingual, mesial and distal measurements was calculated and recorded. (fig 7)

The collected data was statistically analyzed by Microsoft Excel ${ }^{\circledR} 2016^{*}$, Statistical Package for Social Science (SPSS) ${ }^{\circledR}$ Ver. 24** and Minitab ${ }^{* * *}{ }^{\circledR}$ statistical software Ver. 16. Data were revealed as mean and standard deviation further statistically analysis.

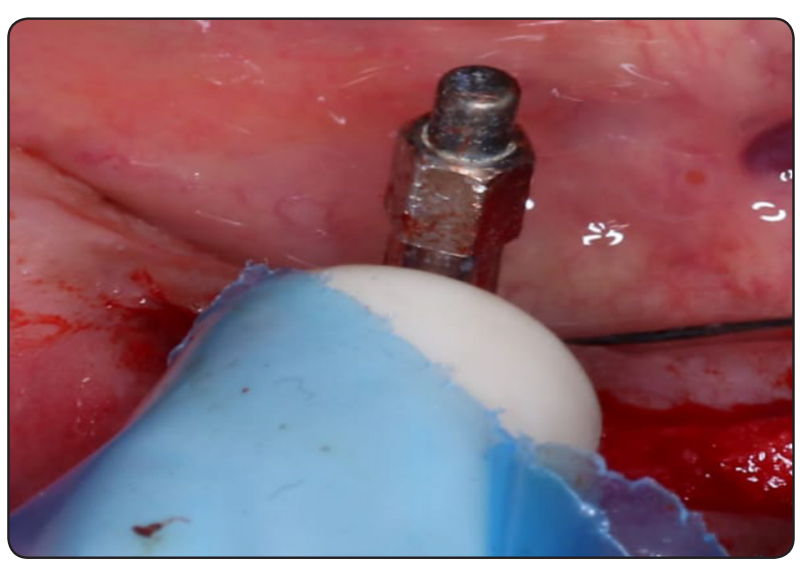

Fig. (7): Smart peg inserted on implant for measurement of stability.

* Microsoft Cooperation, USA.

** IBM Product, USA.

*** Minitab LLC, USA.

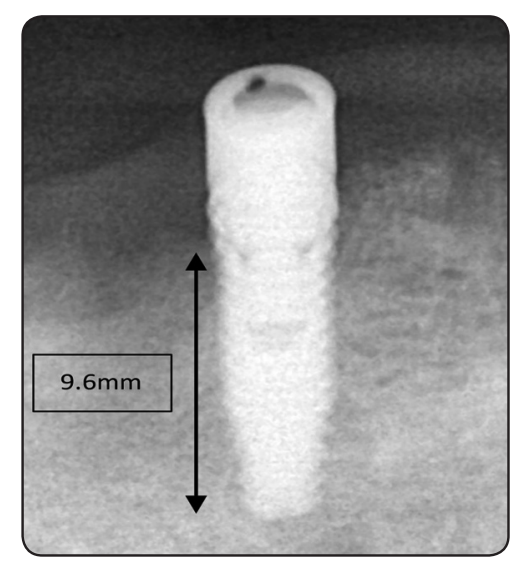

Fig. (6) : Bone height measurement for implant with locator attachment.

\section{RESULTS}

\section{A) Amount of Bone Loss}

Regarding amount of bone loss for locator and ball attachment group, mean \pm standard deviation was $(0.01 \pm 0.00)$ and $(0.00 \pm 0.00)$ respectively at base line which revealed insignificant different using independent $t$ test as P-value $>0.05$. While after one year, mean \pm standard deviation was $(0.032 \pm 0.01)$ and $(0.02 \pm 0.00816)$ respectively which revealed insignificant different using independent $t$ test as $\mathrm{P}$-value $>0.05$. After two years, mean \pm standard deviation was $(0.051 \pm 0.01)$ and $(0.03 \pm 0.00816)$ respectively while after three years, mean \pm standard deviation was $(0.079 \pm 0.01)$ and $(0.045 \pm 0.01291)$ respectively. After four years, mean \pm standard deviation was $(0.083 \pm 0.02)$ and $(0.06 \pm 0.01826)$ respectively. Five years afterwards, mean \pm standard deviation was $(0.19 \pm 0.02)$ and $(0.0725 \pm 0.02062)$ respectively. After six years, mean \pm standard deviation was $(0.56 \pm 0.052)$ and $(0.3275 \pm 0.0515)$ respectively. Finally, after seven years, mean \pm standard deviation was $(0.87 \pm 0.069)$ and $(0.6525 \pm 0.069115)$ respectively. Significant difference was revealed after two, three, four, five, six and seven years using independent $t$ test as $\mathrm{P}$-value $<0.05$, all listed in table (1) and showed in figure (8). 
TABLE (1): Description and Comparison between Locator and Ball Attachment regarding Amount of Bone Loss during Seven Years Follow Up:

\begin{tabular}{cccccc}
\hline & \multicolumn{2}{c}{$\begin{array}{c}\text { Locator } \\
\text { Attachment }\end{array}$} & \multicolumn{2}{c}{$\begin{array}{c}\text { Ball } \\
\text { Attachment }\end{array}$} & P-value \\
\cline { 2 - 5 } & M & SD & M & SD & \\
\hline Baseline & .000 & 0.00 & .0000 & .00000 & $1.000(\mathrm{~ns})$ \\
\hline One Year & .032 & 0.01 & .02 & .00816 & $0.1123(\mathrm{~ns})$ \\
\hline Two Years & .051 & 0.01 & .03 & .00816 & $0.0174 *$ \\
\hline Three Years & .079 & 0.01 & .045 & .01291 & $0.0059^{*}$ \\
\hline Four Years & .083 & 0.02 & .06 & .01826 & $0.014^{*}$ \\
\hline Five Years & .19 & 0.02 & .0725 & .02062 & $0.0002^{*}$ \\
\hline Six Years & .56 & 0.052 & .3275 & .051545 & $0.0007^{*}$ \\
\hline Seven Years & 0.87 & 0.069 & .6525 & .069115 & $0.0043^{*}$ \\
\hline P-value (2) & $<0.0001 *$ & $0.0678(\mathrm{~ns})$ & \\
\hline
\end{tabular}

M; Mean, SD; Standard Deviation, P; Probability Level *significant difference

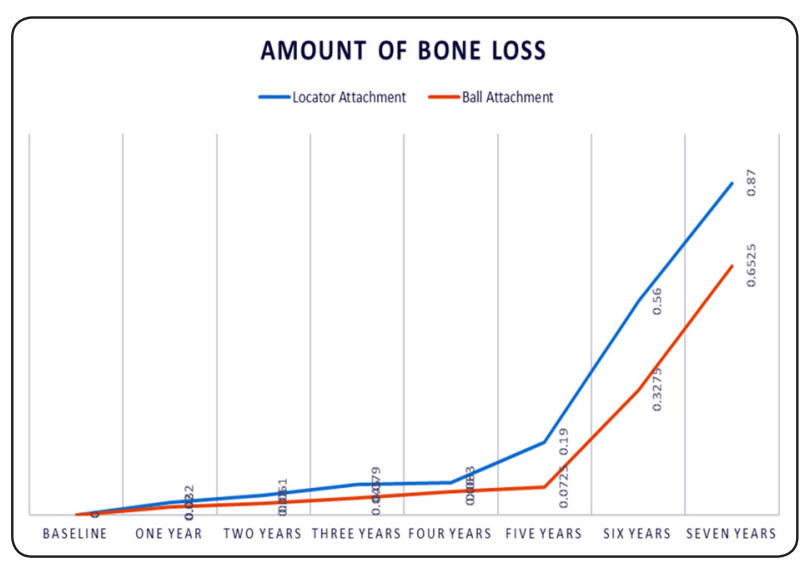

Fig. (8): Line Chart revealing Description and Comparison between Locator and Ball Attachment regarding Amount of Bone Loss during Seven Years Follow Up
Using One Way Analysis of Variance (One Way ANOVA) followed by Tukey's post hoc test for multiple comparisons for definite time intervals, it was revealed that mean difference of each interval in locator attachment was higher than ball attachment among seven years follow up with standard error of difference $(0.02314)$ and $(0.2157)$ respectively with degree of freedom ${ }^{(24)}$, all listed in table (2).

\section{B) ISQ Stability Measurements:}

Regarding implant stability for locator and ball attachment group, mean \pm standard deviation was $(93 \pm 8.81)$ and $(82.5 \pm 6.45)$ respectively at base line. While after one year, mean \pm standard deviation was $(87.65 \pm 6.42)$ and $(81.25 \pm 5.85)$ respectively. After two years, mean \pm standard deviation was $(80.94 \pm 8.93)$ and $(81 \pm 6.48)$ respectively while after three years, mean \pm standard deviation was $(79.18 \pm 7.36)$ and $(80.5 \pm 5.97)$ respectively. After four years, mean \pm standard deviation was $(77.93 \pm 8.97)$ and $(80 \pm 6.48)$ respectively. Five years afterwards, mean \pm standard deviation was $(77.52 \pm 8.5)$ and $(79.25 \pm 6.39)$ respectively. After six years, mean \pm standard deviation was $(76.54 \pm 7.21)$ and (78.5 \pm 5.91$)$ respectively. Finally, after seven years, mean \pm standard deviation was $(75.48 \pm 8.77)$ and $(76.25 \pm 5.56)$ respectively. Insignificant difference was revealed for all follow up periods between both groups using independent $t$ test as P-value $>0.05$, all listed in table (3) and showed in figure (9).

Using One Way Analysis of Variance (One Way ANOVA) followed by Tukey`s post hoc test for multiple comparisons for definite time intervals, it was revealed that mean difference of each interval in locator attachment was higher than ball attachment among seven years follow up with standard error of difference (5.779) and (4.345) respectively with degree of freedom ${ }^{(24)}$, all listed in table (4). 
TABLE (2): Amount of Bone Loss Change between Different Time Intervals regarding Locator Attachment and Ball Attachment Group:

\begin{tabular}{|c|c|c|c|c|c|}
\hline Test details & $\begin{array}{c}\text { MD of Locator } \\
\text { Attachment } \\
\text { Group }\end{array}$ & $\begin{array}{c}\text { SE of Locator } \\
\text { Attachment } \\
\text { Group }\end{array}$ & $\begin{array}{c}\text { MD of Ball } \\
\text { Attachment } \\
\text { Group }\end{array}$ & $\begin{array}{l}\text { SE of Ball } \\
\text { Attachment } \\
\text { Group }\end{array}$ & DF \\
\hline Baseline vs. One Year & -0.03200 & 0.02314 & -0.02 & 0.2157 & 24 \\
\hline Baseline vs. Two Years & -0.05100 & 0.02314 & -0.03 & 0.2157 & 24 \\
\hline Baseline vs. Three Years & -0.07900 & 0.02314 & -0.045 & 0.2157 & 24 \\
\hline Baseline vs. Four Years & -0.08300 & 0.02314 & -0.06 & 0.2157 & 24 \\
\hline Baseline vs. Five Years & -0.1900 & 0.02314 & -0.0725 & 0.2157 & 24 \\
\hline Baseline vs. Six Years & -0.5600 & 0.02314 & -0.3275 & 0.2157 & 24 \\
\hline Baseline vs. Seven Years & -0.8700 & 0.02314 & -0.6525 & 0.2157 & 24 \\
\hline One Year vs. Two Years & -0.01900 & 0.02314 & -0.01 & 0.2157 & 24 \\
\hline One Year vs. Three Years & -0.04700 & 0.02314 & -0.025 & 0.2157 & 24 \\
\hline One Year vs. Four Years & -0.05100 & 0.02314 & -0.04 & 0.2157 & 24 \\
\hline One Year vs. Five Years & -0.1580 & 0.02314 & -0.0525 & 0.2157 & 24 \\
\hline One Year vs. Six Years & -0.5280 & 0.02314 & -0.3075 & 0.2157 & 24 \\
\hline One Year vs. Seven Years & -0.8380 & 0.02314 & -0.6325 & 0.2157 & 24 \\
\hline Two Years vs. Three Years & -0.02800 & 0.02314 & -0.015 & 0.2157 & 24 \\
\hline Two Years vs. Four Years & -0.03200 & 0.02314 & -0.03 & 0.2157 & 24 \\
\hline Two Years vs. Five Years & -0.1390 & 0.02314 & -0.0425 & 0.2157 & 24 \\
\hline Two Years vs. Six Years & -0.5090 & 0.02314 & -0.2975 & 0.2157 & 24 \\
\hline Two Years vs. Seven Years & -0.8190 & 0.02314 & -0.6225 & 0.2157 & 24 \\
\hline Three Years vs. Four Years & -0.004000 & 0.02314 & -0.015 & 0.2157 & 24 \\
\hline Three Years vs. Five Years & -0.1110 & 0.02314 & -0.0275 & 0.2157 & 24 \\
\hline Three Years vs. Six Years & -0.4810 & 0.02314 & -0.2825 & 0.2157 & 24 \\
\hline Three Years vs. Seven Years & -0.7910 & 0.02314 & -0.6075 & 0.2157 & 24 \\
\hline Four Years vs. Five Years & -0.1070 & 0.02314 & -0.0125 & 0.2157 & 24 \\
\hline Four Years vs. Six Years & -0.4770 & 0.02314 & -0.2675 & 0.2157 & 24 \\
\hline Four Years vs. Seven Years & -0.7870 & 0.02314 & -0.5925 & 0.2157 & 24 \\
\hline Five Years vs. Six Years & -0.3700 & 0.02314 & -0.255 & 0.2157 & 24 \\
\hline Five Years vs. Seven Years & -0.6800 & 0.02314 & -0.58 & 0.2157 & 24 \\
\hline Six Years vs. Seven Years & -0.3100 & 0.02314 & -0.325 & 0.2157 & 24 \\
\hline
\end{tabular}

MD; Mean Difference, SE; Standard Error of Difference, DF ; Degree of Freedom 
TABLE (3): Description and Comparison between Locator and Ball Attachment regarding ISQ Stability Measurements during Seven Years Follow Up:

\begin{tabular}{cccccc}
\hline & \multicolumn{2}{c}{ Locator Attachment } & \multicolumn{2}{c}{ Ball Attachment } & P-value (1) \\
\cline { 2 - 5 } & M & SD & M & SD & $0.0664(\mathrm{~ns})$ \\
\hline Baseline & 93.0000 & 8.81 & 82.5000 & 6.45497 & $0.1910(\mathrm{~ns})$ \\
\hline One Year & 87.65 & 6.42 & 81.2500 & 5.85235 & $0.9895(\mathrm{~ns})$ \\
\hline Two Years & 80.94 & 8.93 & 81.0000 & 6.48074 & $0.7533(\mathrm{~ns})$ \\
\hline Three Years & 79.18 & 7.36 & 80.5000 & 5.97216 & $0.6303(\mathrm{~ns})$ \\
\hline Five Years & 77.93 & 8.97 & 80.0000 & 6.48074 & $0.6737(\mathrm{~ns})$ \\
\hline Six Years & 77.52 & 8.50 & 79.2500 & 6.39661 & $0.6087(\mathrm{~ns})$ \\
\hline Seven Years & 76.54 & 7.21 & 78.5000 & 5.91608 & $0.8263(\mathrm{~ns})$ \\
\hline P-value (2) & 75.48 & 8.77 & 76.2500 & 5.56028 & $0.8981(\mathrm{~ns})$ \\
\hline
\end{tabular}

M; Mean, SD; Standard Deviation, P; Probability Level

*significant difference

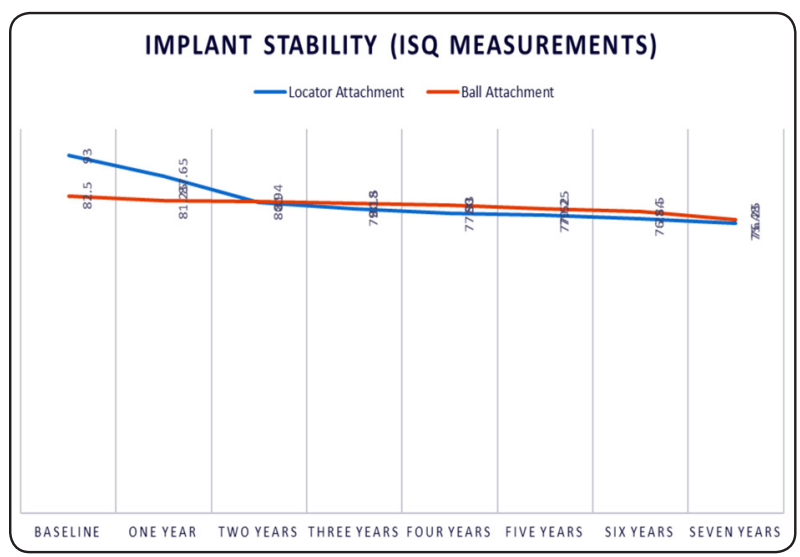

Fig. (9): Line Chart Description and Comparison between Locator and Ball Attachment regarding ISQ Stability Measurements during Seven Years Follow Up 
TABLE (4): Amount of ISQ Stability Measurements Change between Different Time Intervals regarding Locator Attachment and Ball Attachment Group:

\begin{tabular}{|c|c|c|c|c|c|}
\hline Test details & $\begin{array}{l}\text { MD of Locator } \\
\text { Attachment } \\
\text { Group }\end{array}$ & $\begin{array}{c}\text { SE of Locator } \\
\text { Attachment } \\
\text { Group }\end{array}$ & $\begin{array}{l}\text { MD of Ball } \\
\text { Attachment } \\
\text { Group }\end{array}$ & $\begin{array}{c}\text { SE of Ball } \\
\text { Attachment } \\
\text { Group }\end{array}$ & DF \\
\hline Baseline vs. One Year & 5.350 & 5.779 & 1.250 & 4.345 & 24 \\
\hline Baseline vs. Two Years & 12.06 & 5.779 & 1.500 & 4.345 & 24 \\
\hline Baseline vs. Three Years & 13.82 & 5.779 & 2.000 & 4.345 & 24 \\
\hline Baseline vs. Four Years & 15.07 & 5.779 & 2.500 & 4.345 & 24 \\
\hline Baseline vs. Five Years & 15.48 & 5.779 & 3.250 & 4.345 & 24 \\
\hline Baseline vs. Six Years & 16.46 & 5.779 & 4.000 & 4.345 & 24 \\
\hline Baseline vs. Seven Years & 17.52 & 5.779 & 6.250 & 4.345 & 24 \\
\hline One Year vs. Two Years & 6.710 & 5.779 & 0.2500 & 4.345 & 24 \\
\hline One Year vs. Three Years & 8.470 & 5.779 & 0.7500 & 4.345 & 24 \\
\hline One Year vs. Four Years & 9.720 & 5.779 & 1.250 & 4.345 & 24 \\
\hline One Year vs. Five Years & 10.13 & 5.779 & 2.000 & 4.345 & 24 \\
\hline One Year vs. Six Years & 11.11 & 5.779 & 2.750 & 4.345 & 24 \\
\hline One Year vs. Seven Years & 12.17 & 5.779 & 5.000 & 4.345 & 24 \\
\hline Two Years vs. Three Years & 1.760 & 5.779 & 0.5000 & 4.345 & 24 \\
\hline Two Years vs. Four Years & 3.010 & 5.779 & 1.000 & 4.345 & 24 \\
\hline Two Years vs. Five Years & 3.420 & 5.779 & 1.750 & 4.345 & 24 \\
\hline Two Years vs. Six Years & 4.400 & 5.779 & 2.500 & 4.345 & 24 \\
\hline Two Years vs. Seven Years & 5.460 & 5.779 & 4.750 & 4.345 & 24 \\
\hline Three Years vs. Four Years & 1.250 & 5.779 & 0.5000 & 4.345 & 24 \\
\hline Three Years vs. Five Years & 1.660 & 5.779 & 1.250 & 4.345 & 24 \\
\hline Three Years vs. Six Years & 2.640 & 5.779 & 2.000 & 4.345 & 24 \\
\hline Three Years vs. Seven Years & 3.700 & 5.779 & 4.250 & 4.345 & 24 \\
\hline Four Years vs. Five Years & 0.4100 & 5.779 & 0.7500 & 4.345 & 24 \\
\hline Four Years vs. Six Years & 1.390 & 5.779 & 1.500 & 4.345 & 24 \\
\hline Four Years vs. Seven Years & 2.450 & 5.779 & 3.750 & 4.345 & 24 \\
\hline Five Years vs. Six Years & 0.9800 & 5.779 & 0.7500 & 4.345 & 24 \\
\hline Five Years vs. Seven Years & 2.040 & 5.779 & 3.000 & 4.345 & 24 \\
\hline Six Years vs. Seven Years & 1.060 & 5.779 & 2.250 & 4.345 & 24 \\
\hline
\end{tabular}




\section{DISCUSSION}

Restoring the edentulous mandible with implant supported overdentures has proven to be a successful treatment option that provides the patient with a stable, retentive denture, with better esthetics, function and patient satisfaction ${ }^{18,19}$.

Implant retained mandibular overdentures on two solitary implants is the treatment of choice for many practitioners. It is not only less time consuming and cheaper, but it also allows movement of the denture in the distal extension areas, reducing the loads on the implants and transferring part of the stresses onto the posterior alveolar ridge ${ }^{7}$. However, this consequently generates the need for frequent maintenance due to the inherent movement of the denture 20,21 .

Four solitary implants can provide a more stable and retentive denture, with less movement during function. This however, is expected to produce more load on the implants, which can be seen in the results of the present study, where there is statistically significant bone loss surrounding the distal implants after seven years of function regardless of the type of attachment used. This comes in accordance with other studies, that reported more bone loss with 4 implant overdentures when compared to two-implant overdentures, probably due to the cantilever-like effect exerted by the overdenture during function 22,23 .

It is worth mentioning that this bone loss might have been less if the four implants were splinted by a bar, to allow distribution of forces between the implants ${ }^{24,25}$.

The results of the current study have also shown that the bone loss with the locator attachment was higher than the ball attachment, which might be attributed to the fact that ball attachments allow more denture movement due to their nature ${ }^{26,27}$.

The results have also shown that although bone loss surrounding the distal implants was significant, implant stability remained high as measured during the follow-up intervals over seven years. This comes in accordance with many studies confirming the long-term success of implant overdentures irrespective of the type of attachment used 7,28,29.

\section{CONCLUSION}

Long term follow up on mandibular overdentures supported by four solitary implants, regardless of the attachment, have shown good implant stability, however, significant bone loss around the most distal implants is to be expected.

\section{REFERENCES}

1. Albaker AM. The oral health-related quality of life in edentulous patients treated with Conventional complete dentures. Gerodontology 2013; 30: 61-66.

2. Allen PF, McMillan AS. A longitudinal study of quality of life outcomes in older adults requesting implant prostheses and complete removable dentures. Clin Oral Implants Res 2003; 14: 173-179.

3. Feine JS, Carlsson GE, Awad MA, et al. The McGill consensus statement on overdentures. Quintessence Int (Berl) 2003; 34: 78-79.

4. N. A, A.G.T. P, R.K. DS, et al. Mandibular single-implant overdentures: A review with surgical and prosthodontic perspectives of a novel approach. Clinical Oral Implants Research 2009; 20: 356-365.

5. Hartmann R, de Menezes Bandeira ACF, de Araújo SC, et al. Cost-effectiveness of three different concepts for the rehabilitation of edentulous mandibles: Overdentures with 1 or 2 implant attachments and hybrid prosthesis on four implants. J Oral Rehabil 2020; 47: 1394-1402.

6. M.C. C, S. U, K. A. Marginal bone level changes and prosthetic maintenance of mandibular overdentures supported by 2 implants: A 5-Year randomized clinical trial. Clinical Implant Dentistry and Related Research 2010; 12: 114-121.

7. Meijer HJA, Raghoebar GM, Batenburg RHK, et al. Mandibular overdentures supported by two or four endosseous implants: A 10-year clinical trial. Clin Oral Implants Res 2009; 20: 722-728.

8. Kern JS, Kern T, Wolfart S, et al. A systematic review and meta-analysis of removable and fixed implant-supported 
prostheses in edentulous jaws: Post-loading implant loss. Clinical Oral Implants Research 2016; 27: 174-195.

9. Klemetti E. Is there a certain number of implants needed to retain an overdenture? J Oral Rehabil 2008; 35: 80-84.

10. ELsyad M, Agha N, Habib A. Retention and Stability of Implant-Retained Mandibular Overdentures Using Different Types of Resilient Attachments: An In Vitro Study. Int J Oral Maxillofac Implants 2016; 1040-1048.

11. Savabi O, Nejatidanesh F, Yordshahian F. Retention of implant-supported overdenture with bar/clip and stud attachment designs. J Oral Implantol 2013; 39: 140-147.

12. Miler AMQP, Correia ARM, Rocha JM de C, et al. Locator ${ }^{\circledR}$ attachment system for implant overdentures: a systematic review. Stomatologija 2017; 19: 124-129.

13. Albrektsson T. On long-term maintenance of the osseointegrated response. Australian prosthodontic journal / Australian Prosthodontic Society 1993; 7 Suppl: 15-24.

14. Meredith N, Book K, Friberg B, et al. Resonance frequency measurements of implant stability in vivo: A crosssectional and longitudinal study of resonance frequency measurements on implants in the edentulous and partially dentate maxilla. Clin Oral Implants Res 1997; 8: 226-233.

15. Jaramillo R, Santos R, Lázaro P, et al. Comparative analysis of 2 resonance frequency measurement devices: Osstell mentor and osstell ISQ. Implant Dent 2014; 23: 351-356.

16. Krafft T, Graef F, Karl M. Osstell resonance frequency measurement values as a prognostic factor in implant dentistry. J Oral Implantol 2015; 41: e133-e137.

17. Herrero-Climent M, Santos-García R, Jaramillo-Santos R, et al. Assessment of Osstell ISQ's reliability for implant stability measurement: A cross-sectional clinical study. Med Oral Patol Oral Cir Bucal; 18. Epub ahead of print 2013. DOI: $10.4317 /$ medoral.19120.

18. Kutkut A, Bertoli E, Frazer R, et al. A systematic review of studies comparing conventional complete denture and implant retained overdenture. Journal of Prosthodontic Research 2018; 62: 1-9.

19. Wennerberg A, Albrektsson T. Current challenges in successful rehabilitation with oral implants. Journal of Oral Rehabilitation 2011; 38: 286-294.
20. Alsabeeha NHM, Payne AGT, De Silva RK, et al. Mandibular single-implant overdentures: Preliminary results of a randomised-control trial on early loading with different implant diameters and attachment systems. Clin Oral Implants Res 2011; 22: 330-337.

21. Watson GK, Payne AG, Purton DG TW. Mandibular overdentures: comparative evaluation of prosthodontic maintenance of three different implant systems during the first year of service. Int J Prosthodont 2002; 15: 259-66.

22. Stoker G, Van Waas R, Wismeijer D. Long-term outcomes of three types of implant-supported mandibular overdentures in smokers. Clin Oral Implants Res 2012; 23: 925-929.

23. Bilhan H, Mumcu E, Arat S. The comparison of marginal bone loss around mandibular overdenture- supporting implants with two different attachment types in a loading period of 36 months. Gerodontology 2011; 28: 49-57.

24. Naert I, Alsaadi G, van Steenberghe D, et al. A 10-year randomized clinical trial on the influence of splinted and unsplinted oral implants retaining mandibular overdentures: peri-implant outcome. Int J Oral Maxillofac Implants 2004; 19: 695-702.

25. Heschl A, Payer M, Clar V, Stopper M, Wegscheider W LM. Overdentures in the edentulous mandible supported by implants and retained by a Dolder bar: a 5-year prospective study. lin Implant Dent Relat Res 2013; 15: 589-99.

26. El-Anwar MI, Yousief SA, Soliman TA, et al. A finite element study on stress distribution of two different attachment designs under implant supported overdenture. Saudi Dent J 2015; 27: 201-207.

27. Tokuhisa M, Matsushita Y, Koyano K. In Vitro Study of a Mandibular Implant Overdenture Retained with Ball, Magnet, or Bar Attachments: Comparison of Load Transfer and Denture Stability. Int J Prosthodont 2003; 16: 128-134.

28. Muhammad Ikbal, Acing Habibie Mude, Irfan Dammar, Vinsensia Launardo, Ian Afifah Sudarman Locator or Ball Attachment Systems for Mandibular Implant Overdentures: A Systematic Review . Systematic Reviews in Pharmacy, Sept-Oct 2020, Vol 11, Issue 9.

29. Sachin H and Smruti T. A systematic review and meta-analysis of the attachments used in implant-supported overdentures. J Indian Prosthodont Soc, Jul-Sep 2020;20(3):255-268 